\title{
Health Seeking Behavior among Patients with Tuberculosis in Dr. Hasan Sadikin General Hospital Bandung, Indonesia in November 2012
}

\author{
Maya Valentina Putrie, ${ }^{1}$ Rovina Ruslami, ${ }^{2}$ Lika Apriani ${ }^{3}$ \\ ${ }^{1}$ Faculty of Medicine Universitas Padjadjaran, ${ }^{2}$ Department of Pharmacology and Therapy, \\ Faculty of Medicine Universitas Padjadjaran, ${ }^{3}$ Department of Epidemiology and Biostatistics, \\ Faculty of Medicine Universitas Padjadjaran
}

\begin{abstract}
Background: Dr. Hasan Sadikin General Hospital is the main referral hospital in West Java, Indonesia, treating yearly 1.000 tuberculosis cases of whom most are in severe condition. The severity of the disease is probably affected by the poor patient's health seeking behavior.The objective of this study was to assess the pattern of patients with tuberculosis's health seeking behavior before being treated in Dr. Hasan Sadikin General Hospital, Bandung.

Methods: A descriptive study was carried out in November 2012 on 56 patients in the Drug Observed Treatment Shortcourse (DOTS) Clinic at Dr. Hasan Sadikin General Hospital (RSHS) to assess the number and type of health services visited prior to RSHS. The inclusion criteria were patients who were diagnosed with TB for the first time, aged at least 19 years old. The data were collected using an open-ended questionnaire and presented as percentage.

Results: A total of 32 respondents (57\%) sought for initial treatment by going to professional health care centers (the medical doctors, puskesmas, or hospitals), the rests sought for traditional treatment (7\%), selftreatment (29\%), or no medication prior to the treatment at RSHS (7\%). Fifty five percent of respondents did more than one type of health seeking behavior. The average time between the first complaint until the respondents got treatment was 5 months.

Conclusions: The patients with tuberculosis's treatment seeking behavior is various prior to the treatment at RSHS and there are still patients who seek treatments to the non-profesional health care.
\end{abstract}

Keywords: Health seeking behavior, treatment, tuberculosis

Correspondence: Maya Valentina Putrie, Faculty of Medicine, Universitas Padjadjaran, Jalan Raya Bandung-Sumedang Km.21, Jatinangor, Sumedang, Indonesia, Phone: +6289607727249 Email: putrie_valentina@yahoo.com 